\title{
HARDNESS AND TENSILE BEHAVIOR OF FRICTION STIR WELDED ALUMINUM AA6351 ALLOY
}

\author{
G. Gopala Krishna ${ }^{1, *}$, P. Ram Reddy ${ }^{2}$, and M. Manzoor Hussain ${ }^{3}$ \\ ${ }^{1}$ Department of Mechanical Engineering, J.B. Institute of Engineering and Technology, \\ Yenkapally, Moinabad, Hyderabad 500 075, Andhra Pradesh, India \\ ${ }^{2}$ Malla Reddy College of Engineering \& Technology, Hyderabad, A.P., India \\ ${ }^{3}$ JNTUH College of Engineering, Sulthanpur, Medak District, A.P., India \\ *Corresponding e-mail: krishkans@gmail.com
}

\begin{abstract}
Friction Stir Welding (FSW) is a solid state welding process gaining more applications in various industries due to better quality of the joint as it has no effect on parent metal. In FSW process a non consumable rotating welding tool is used to generate frictional heat between tool and abutting surface of work piece and plastic dissipation of energy to accomplish the weld. Being a solid state joining process, friction stir welding process offers various advantages like low distortion, absence of melt related defects, high joint strength etc. as compared to other conventional fusion welding techniques.

Experiments were conducted on 6 mm thickness Aluminum AA6351-T4, commercially available plates. These plates are joined by FSW along the rolling direction (longitudinal weld orientation) and across the rolling direction (transverse weld orientation). The hardness and tensile strength results of the weldments are presented. Results show superior mechanical properties for the joints with plates along the rolling direction as compared with the joints obtained by across the rolling direction.
\end{abstract}

Keywords: Friction Stir Welding, Aluminum AA6351 Alloy, Hardness and Tensile Strength.

\section{INTRODUCTION}

Aluminum and its alloys are widely used in many industrial applications such as aerospace, shipbuilding, automotive industries etc. due to their strength and light weight ${ }^{1}$. But the welding of aluminum and its alloys has always possess a great challenge for designers and technologists as these alloys, especially heat treatable aluminum alloys are difficult to join by conventional fusion welding techniques. This is because some welding defects such as crack and porosity are easily formed in the weld during solidification of the welding pool ${ }^{2}$. Moreover, the conventional welding techniques often lead to significant strength deterioration and mechanical properties degradation in the welded joint as phase transformation and softening induced in the alloy.

Friction Stir Welding (FSW) process is a promising alternate technology for welding aluminum and its alloys especially heat treatable aluminum alloys that can produce low cost and high quality of the joint ${ }^{3}$. This process is well suited for joining all types of aluminum and its alloys particularly those usually considered unweldable such as 2000 and 7000 series $^{4,5}$. Friction stir welding process is not only suited for aluminum alloys but also suits for all other materials including steels and composites.

Friction Stir Welding is fairly new welding technology developed and patented by The Welding Institute (TWI), United Kingdom in December $1991^{6,7}$. This is a solid phase joining process that takes place below the melting point of the materials to be joined ${ }^{2}$. The basic principle of FSW is remarkably simple and is shown in Fig. 1. A rotating tool with shoulder and pin is inserted in the material to be joined and traversed along the line of the joint. The heating is localized and generated by friction between tool and the work piece, with additional adiabatic heating from metal deformation. The shoulder and pin of the tool can be modified in a number of ways to influence material flow and microstructural evolution. The important advantages of FSW are low distortion, absence of melt related defects, high joint strength and absence of filler induced problems since the technique requires no filler.

FSW technique can be used to produce lap, butt, corner, T, spot, fillet and hem joints as well as to weld hollow objects, such as pipe/tube and tanks and parts with 3-dimensional contours ${ }^{6}$. Replacement of mechanical fastened joints with FS welded joints can lead to significant weight and cost savings, attractive for many industries. By using FS welded joints instead of fastened joints can also eliminate the stress concentration effects associated with fastener holes, improve corrosion performance by eliminating the fasteners as a source of dissimilar metal contact.

The general profile of butt joint was proposed by $\mathrm{TWI}^{10}$, is an inverted trapezoid displaying four zones as shown in Fig. 2. They are unaffected material, heat affected zone (HAZ), thermo mechanically affected zone (TMAZ), and weld nugget. The unaffected material or parent metal (A), which is remote from the weld, where no microstructural or mechanical 
property changes took place. The heat affected zone (B), which clearly lie closer to the weld centre, where the material experienced no plastic deformation but was influenced by the heat of welding, leading to some microstructural changes. The thermo mechanically affected heat zone $(\mathrm{C})$, where the material has deformed plastically and was also influenced by heat. The weld nugget (D), which is recrystallized region of the TMAZ ${ }^{11,12}$.

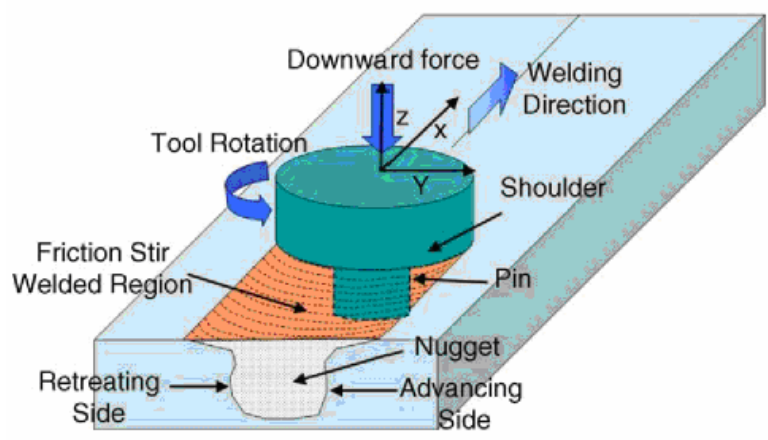

Figure1. Schematic drawing of friction stir welding ${ }^{8}$.

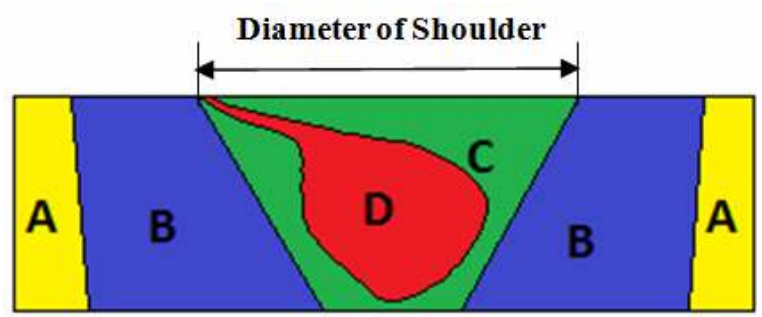

Figure 2. Simplified diagram illustrating macrostructure of weld zone. Here, A - Unaffected Material or Parent Metal, B - Heat Affected Zone (HAZ), C - Thermo Mechanical Affected Zone (TMAZ), D - Weld Nugget (Part of Thermo Mechanical Affected Zone).

\section{EXPERIMENTAL PROCEDURE}

\section{Material}

The base material for this investigation was AA6351 aluminum alloy. Procured material is cut into pieces with the size of $150 \times 60 \mathrm{~mm}$ and thickness $6 \mathrm{~mm}$ for processing. A CNC milling machine is used for friction stir welding of 6351 alloy

Aluminum alloy AA6351 is a medium strength alloy with excellent corrosion resistance. It has the highest strength of all 6000 series alloys ${ }^{13}$. Alloy 6351 is identified as a structural alloy because it's many applications in different structures. AA 6351 is the alloy most commonly used for machining in plate form. Though this is a relatively new alloy, the higher strength of 6351 has been replacing 6061 in many applications. AA 6351 becomes stronger alloy by addition of large amount of manganese as it controls the grain structure.

The standard and experimental chemical composition of aluminum AA6351 are listed in following table 1 and 2 respectively. Mechanical and physical properties of aluminum AA6351 also are listed in table 3 and 4 respectively.

\section{Welding Procedure}

A 3-axis vertical CNC milling machine is converted into a Friction Stir Welding machine with an attachment of work holding fixture for welding of aluminum AA6351 alloy. The Specifications of CNC milling machine: Vertical Axes CNC 3 - Axes Machining Center (OKUMA), Model: MD 56 VA, Spindle driver: Servo motor, Spindle range: 50-8000 rpm, Tool Holder: BT 40, Tool Material: HSS, Movement: 610 X 450mm, Bed Size: 560 X 1300 $\mathrm{mm}$.

Two pieces to be welded, with square mating edges, are brought into contact, placed on a backing plate and firmly clamped. A specially designed non

Table.1 Standard Chemical Composition

\begin{tabular}{|c|c|c|c|c|c|c|c|}
\hline $\mathbf{S i}$ & $\mathbf{F e}$ & $\mathbf{C u}$ & $\mathbf{M n}$ & $\mathbf{M g}$ & $\mathbf{Z n}$ & $\mathbf{T i}$ & Al \\
\hline $0.07-1.3$ & 0.5 & 0.1 & $0.4-0.8$ & $0.4-0.8$ & 0.2 & 0.2 & balance \\
\hline
\end{tabular}

Table.2 Experimental Chemical Composition

\begin{tabular}{|c|c|c|c|c|c|c|c|c|}
\hline $\mathbf{M n}$ & $\mathbf{S i}$ & $\mathbf{C r}$ & $\mathbf{T i}$ & $\mathbf{C u}$ & $\mathbf{Z n}$ & $\mathbf{M g}$ & $\mathbf{F e}$ & $\mathbf{A l}$ \\
\hline 0.57 & 0.93 & 0.006 & 0.014 & 0.1 & 0.134 & 0.55 & 0.36 & balance \\
\hline
\end{tabular}

Table 3. Mechanical Properties

\begin{tabular}{|c|c|c|c|c|c|c|c|}
\hline \multirow{2}{*}{ Alloy } & Temperature & $\begin{array}{c}\text { Tensile } \\
\text { Strength } \\
\mathbf{( M P a )}\end{array}$ & $\begin{array}{c}\text { Yield } \\
\text { Strength } \\
\mathbf{( M P a )}\end{array}$ & $\begin{array}{c}\text { Elongation } \\
\mathbf{( \% )}\end{array}$ & Hardness & $\begin{array}{c}\text { Shear } \\
\text { Strength } \\
\mathbf{( M P a )}\end{array}$ & $\begin{array}{c}\text { Fatigue } \\
\text { Strength } \\
\mathbf{( M P a )}\end{array}$ \\
\hline \multirow{2}{*}{6351} & $\mathrm{~T} 4$ & 250 & 150 & 20 & - & - & - \\
\cline { 2 - 8 } & $\mathrm{T} 6$ & 310 & 285 & 14 & 95 & 200 & 90 \\
\hline
\end{tabular}

Table 4. Physical Properties

\begin{tabular}{|c|c|c|c|c|c|}
\hline Density & Melting Point & $\begin{array}{c}\text { Modulus of } \\
\text { Elasticity }\end{array}$ & $\begin{array}{c}\text { Electrical } \\
\text { Resistivity }\end{array}$ & $\begin{array}{c}\text { Thermal } \\
\text { Conductivity }\end{array}$ & $\begin{array}{c}\text { Thermal } \\
\text { Expansion }\end{array}$ \\
\hline $2.7 \mathrm{~g} / \mathrm{cm}^{2}$ & $555^{\circ} \mathrm{C}$ & $70 \mathrm{GPa}$ & $0.038 \times 10^{-6} \Omega \mathrm{m}$ & $172 \mathrm{~W} / \mathrm{m}^{\circ} \mathrm{K}$ & $46 \times 10^{-6} / \mathrm{K}$ \\
\hline
\end{tabular}


consumable cylindrical welding tool (harder than metal to be welded) consisting of larger diameter shoulder and a smaller threaded pin is inserted into work piece to be welded. During the welding process, the rotation of the shoulder which is in contact with the upper surface of the work piece and the pin produces large stirring action and frictional heat bringing the material to a plasticized state. As the tool translates along the welded joint line, the plasticized material is stirred and forged behind the trialing face of the pin, where it consolidates and cools down to form the solid state weld ${ }^{9}$.

The rotational speeds of the tool were selected as 600,700 and $800 \mathrm{rpm}$ in the tests. Plates were moved at 12 and $16 \mathrm{~mm} / \mathrm{min}$ feed rates (welding speed). Microhardness (Vickers's hardness) and tensile tests (of along the roll direction and across roll direction) were conducted to measure the mechanical properties of the welded joint.

\section{RESULTS AND DISCUSSIONS}

In this study, Aluminum AA 6351 alloy joints were welded successfully by friction stir welding process by using three different rotational speeds and two different feeds of the tool. Some interesting developments of mechanical properties have been observed in the weldments. The Vicker's Hardness Number and tensile testing of the weld is influenced by rotational speed and feed of the tool. The effects of rotational speed and feed of the tool towards the Vicker's hardness and tensile testing of the joints were investigated.

Table 5. Selected welding parameters

\begin{tabular}{|l|l|}
\hline Process Parameter & Values \\
\hline Rotational Speed $(\mathrm{rpm})$ & 600,700 and 800 \\
\hline Welding Speed $(\mathrm{mm} / \mathrm{min})$ & 12 and 16 \\
\hline Tool Material & $\begin{array}{l}\text { High Speed Steel } \\
\text { with 54 HRC }\end{array}$ \\
\hline
\end{tabular}

The results of the tests are shown in graphs below for the specimen prepared using friction stir welded joints. A lower rotation speed gives rise to an insufficient increase in temperature at the weld, so that the pin wore out in a short time. At a higher rotation speed of the tool, the temperature increase was so excessive that the Magnesium in the Aluminum alloy oxidized and resulted in an unsound joint.

\section{Hardness Test}

The weld joint is tested for hardness along and across the weld direction and the obtained Vicker's Hardness Numbers (VHN) is plotted in graph as shown in Fig. 3. The hardness of the base material $(\mathrm{BM})$ is found to be uniform along and across the weld direction. The hardness profile across the weld direction indicates a sudden increase from the base metal hardness to thermo mechanical affected zone
(TMAZ) and Heat Affected Zone (HAZ) ${ }^{14,15}$, varies constantly in the advancing side of the weld and a steep drop in hardness is observed in the weld nugget zone and a similar drop in retreating side of the weldment.

This may be due to the difference in the tool rotation velocity vector and the tool feed direction vector. High value of hardness in the advancing side is noted due to recrystallization, fine dispersing and diffusion of the copper particles in to the aluminum matrix leading to fine equivaxed smaller grains. The failure of tensile test specimens in TMAZ on retreading side also substantiates the possibility of minimum hardness.

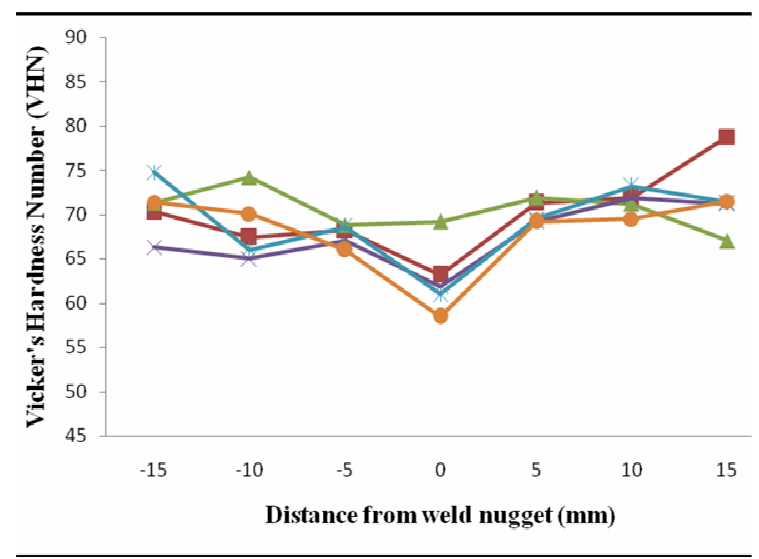

Figure 3. Vicker's hardness distribution over FS welded joints.

\section{Tensile Test}

The specimens for tensile tests were prepared as per ASTM (American Society for Testing Materials) standard norms. E8 standard test specimens of gauge length $25 \mathrm{~mm}$ has been extracted in longitudinal direction and transverse orientation of the weld in wire cut EDM (Electric Discharge Machining) machine. The test samples were tested on an Instron UTM (Universal Testing Machine). The graphs are plotted for tensile strengths along and across the weld direction with the acquired results and they are presented in Fig. 4 and 5 respectively. The obtained results show a considerable improvement in the joint strength in tension both along and across the weld direction. The tensile strength of the joints along the roll direction (parallel to the roll direction) shows superior tensile strength values as compared to the joints across the roll direction (perpendicular to weld direction). This may be due to the reason that anisotropy of the process, thereby improving the tensile strength properties. The fracture location observed to be in between the heat affected zone (HAZ) and thermo mechanically affected zone (TMAZ) on the retreating side of the joint apparently depends on the anisotropic behavior of the material due to the rolling process performed before friction stir welding. 


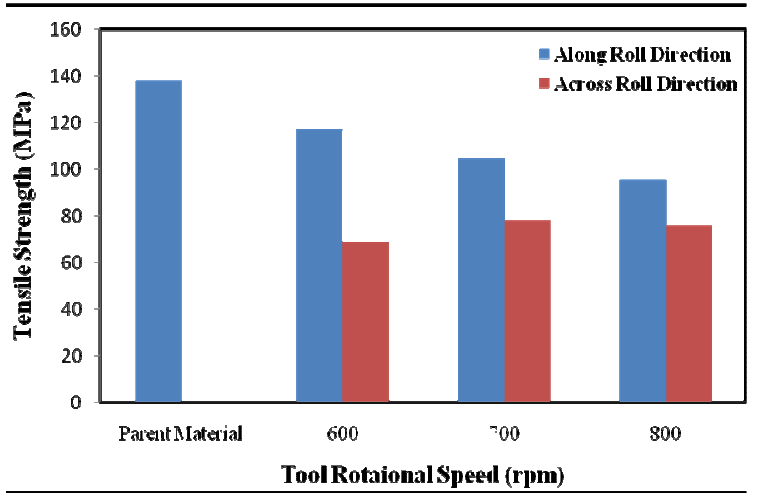

Figure 4. Tensile Test graphs - Tool Rotational Speed Vs Tensile Strength (for feed $12 \mathrm{~mm} / \mathrm{min}$ ).

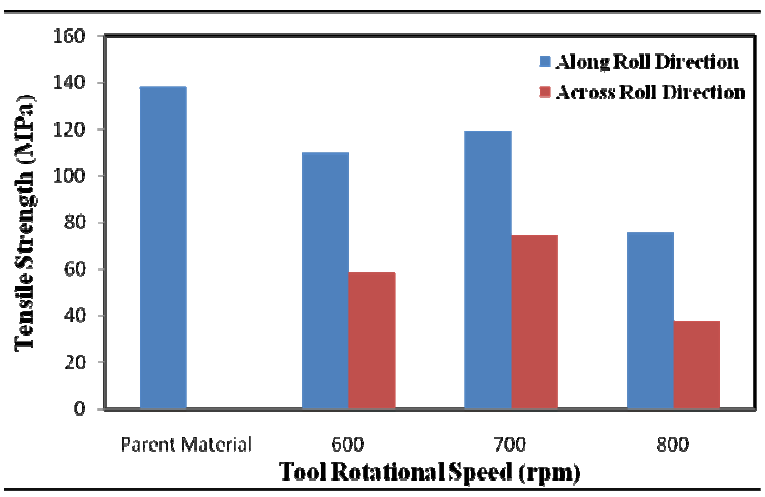

Figure 5. Tensile Test graphs - Tool Rotational Speed Vs Tensile Strength (for feed $16 \mathrm{~mm} / \mathrm{min}$ ).

\section{CONCLUSIONS}

- The effect of the rolling direction with respect to that of the welding direction on the mechanical behavior of the friction stir welded AA 6351 plates were done experimentally and the results are reported successfully.

- The tensile strength of the parent material is observed to be much higher than the weldments made along and across the weld direction. The weldments made parallel to the roll direction have much superior tensile strength as compared to the one made perpendicular to the roll direction.

- The tension tests conducted on the specimens reveal that the strength of the weldments along the rolling direction with an increase in ductility and a reduction in necking value demonstrating the influence of anisotropy of AA 6351 alloy in friction stir welding.

- The microhardness profile shows a steep down in WZ and increases in TMAZ and HAZ due to softening behavior of the material around the friction stir weldments. The hardness profiles are plotted as a function of various tool speed and the positions with respect to the weld nugget zone.

\section{REFERENCES}

1.W.M. Thomas, E.D. Nicholas, 1997, "Friction stir welding industries", Mater Des 18(4/): 269-273.

2. C.J. Dawes, W.M. Thomas, 1996, "Friction stir process welds aluminum alloys", Weld. J. 75 41-45.

3. H.J. Liu, H. Fujii, M. Maeda, K. Nogi, 2003, "Tensile properties and fracture locations of friction stir welded joints of 2017-T351 aluminum alloy", J. of Material Processing Technology, vol. 142, pp. 692-696.

4. O.V. Flores, C. Kennedy, L.E. Murr, D. Brown, S. Pappu, B.M. Nowak, 1998, "Microstructural issues in a friction-stir-welded aluminum alloy". Scripta Mater 38(5): 703-708.

5. L.E. Murr, G. liu, J.C. McClure, 1998, “A TEM study of precipitation and related microstructures in friction-stir-welded 6061 aluminum", J. Mater Sci 33(5): 1243-1251.

6. W.M. Thomas, E.D. Nicholas, J.C. Needham, M.G. Murch, P. Templesmith, C.J. Dawes, 1991, G.B. Patent Application No. 9125978.8.

7. C. Dawes, W. Thomas, TWI Bulletin, 1995, 124.

8. R.S. Mishra and Z.Y. Mictioa, 2005, "Friction stir welding and processing - Research" Mater. Sci. Eng., R, vol. R50, pp. 1-78.

9. O.T. Miding, L.D. Oosterkamp, J. Bersaas, "Friction stir welding aluminum - process and applications", Proceedings of the $7^{\text {th }}$ Int. Conference on Joints in Aluminum (INALCO'98), Cambridge, England, vol.2. p. 161-171.

10. TWI web site. $w w w . t w i . c o . u k$.

11. T. Khaleed, July 2005, "An outsider looks at friction stir welding", ANM-112N-05-06.

12. N. Singh, R. Singh and H. Lal, 2013, "Experimental study of friction stir welding of aluminium alloy (A1100 \& A6101)”, vol.1, issue.1.

13. A.K. Hussain, S.A.P. Quadri, 2010, "Evaluation of parameters of friction stir welding for aluminum AA6351 alloy", Int. J. of Engineering Science and Technology, vol. 2 (10), pp.5977-5984.

14. A.A. Zadpur, J. Sinke, R. Benedictus, R. Pieters, 2008, "Mechanical properties and microstructure of friction stir welded tailor-made blanks", Material Science and Engineering A, 494, pp. 281-290.

15. C. Leitro, R.M. Leal, D.M. Rodrigues, A. Loureiro, P. Vilaca, 2009, "Mechanical behavior of similar and dissimilar AA5182-H111 and AA6016T4 thin friction stir welds", Materials and Design, 30, pp. 101-108. 